\title{
"To Shave or Not to Shave": Pubic Hair Removal and Its Association with Relational and Sexual Satisfaction in Women and Men
}

\author{
Paul Enzlin, PhD, ${ }^{1,2}$ Kaat Bollen, MSc, Sofia Prekatsounaki, MSc, 'Liesbeth Hidalgo, MSc, Leen Aerts, MD, PhD, ${ }^{1,3}$
} and Jan Deprest, $\mathrm{MD}, \mathrm{PhD}^{4,5}$

\begin{abstract}
Background: Pubic hair removal (PHR) is a widespread practice that entails certain health risks; however, there remains a lack of scientific information on the prevalence and antecedents of PHR, as well as on its association with sexual behavior and relational satisfaction.
\end{abstract}

Aims: To explore women's and men's attitudes regarding PHR and their PHR practices and the associations with demographic, relational, and sexual characteristics.

Methods: A total of 2,687 men and 1,735 women living in Flanders (the Northern part of Belgium) completed an online survey. Participants ranged in age from 15 to $60+$ years; they self-identified as heterosexual, bisexual, or homosexual and reported various relationship statuses.

Main Outcome Measures: Demographic items (ie, age, religion, partner relationship status), sexuality-related items (ie, sexual activity, sexual orientation, age at first intercourse, number of sexual partners), PHR items (ie, reasons, inclination to have or not have sex after PHR, perceived partner preferences, partner's PHR), and relationship satisfaction, assessed with the Maudsley Marital Questionnaire.

Results: Fewer men $(39.1 \%)$ than women $(80.3 \%)$ reported (partially) removing their pubic hair. In both men and women, the practice was associated with age, sexual activity, relationship status, and partner's PHR practice and expectations. In men, sexual and relationship satisfaction were correlated with their partner's PHR practices and whether these were in line with the men's expectations. In women, sexual and relationship satisfaction were mostly correlated with whether both partner's expectations were met. Although both men and women reported that the reasons for PHR were related to their sexual experiences and to their partner's preference, only women reported that PHR was a way to enhance feelings of femininity. Finally, the reasons for not engaging in PHR were related to partner preferences and side effects.

Conclusion: PHR is a widespread practice and seems strongly associated with personal, partner-related, sexual, and relational factors. Strategies to prevent men and women from being confronted with health risks should take all these factors into account. Enzlin P, Bollen K, Prekatsounaki S, et al. "To Shave or Not to Shave": Pubic Hair Removal and Its Association with Relational and Sexual Satisfaction in Women and Men. J Sex Med 2019;XX:XXX-XXX.

Copyright (C) 2019, International Society for Sexual Medicine. Published by Elsevier Inc. All rights reserved.

Key Words: Pubic Hair Removal; Prevalence; Sexual Behavior; Relational Satisfaction; Men; Women

Received August 20, 2018. Accepted April 4, 2019.

'Institute for Family and Sexuality Studies, Department of Neurosciences, KU Leuven, Leuven, Belgium;

${ }^{2}$ Center for Clinical Sexology and Sex Therapy, UPC KU Leuven, Leuven, Belgium;

${ }^{3}$ Geneva University Hospitals, Boulevard de la Cluse 30, 1205 Geneva, Switzerland;

${ }^{4}$ Department of Development and Regeneration, Cluster Woman and Child, KU Leuven, Leuven, Belgium;

${ }^{5}$ Institute for Women's Health, University College London, London, United Kingdom

Copyright @ 2019 , International Society for Sexual Medicine. Published by Elsevier Inc. All rights reserved.

https://doi.org/10.1016/j.jsxm.2019.04.005

\section{INTRODUCTION}

Various cultural, artistic and historical accounts have shown that in several cultures, pubic hair removal (PHR) remains a widespread practice, especially among women. ${ }^{1}$ In Western cultures, the prevalence of PHR is increasing, a trend accompanied by an increasing incidence of PHR injuries. ${ }^{2}$ Indeed, complications related to PHR are common, ${ }^{3,4}$ and PHR may even be a risk factor for the transmission of (minor) sexually transmitted infections. ${ }^{5,6}$ Although this implies that PHR is relevant for sexual medicine practitioners, there remains a lack of information on its prevalence and associated factors, information that could be helpful for educating men and women 
about PHR in an attempt to prevent (sexual) health-related issues.

Until now, most research on the personal, relational, and behavioral correlates of PHR has focused on women. Previous studies have shown that the current prevalence of PHR is very high ranging between $47.9 \%$ and $87.6 \%$ among women in the United States, ${ }^{7-10}$ United Kingdom, ${ }^{11,12}$ and Australia. ${ }^{13}$ Although hairlessness has traditionally been associated with femininity-implying that body depilation is less common in men ${ }^{14}$ - the scarce body of research on the subject suggests that men also engage in pubic hair modification. ${ }^{14-16}$ However, little is known about the prevalence of PHR practices and their associated factors in men, as well as about possible differences in attitudes toward PHR between women and men.

From previous research, it is known that PHR is associated with younger age, a heterosexual or bisexual orientation, and being partnered. ${ }^{8-10,16}$ PHR also has been found to be associated with sexual activity, sexual behavior, and sexual function; studies have shown that both men and women are more likely to remove their pubic hair when sexual activity was more likely to occur. $^{7,9,16,17}$ In addition, in women, PHR has been linked to such sexual variables as interest in sex, receipt of oral sex, genital self-stimulation, and sexual functioning. ${ }^{9,10}$ Finally, it has even been suggested that PHR may reflect or influence women's sexual decision making. ${ }^{10}$

Although this is all very interesting, most scientific research on the subject has been conducted in the United States, United Kingdom, and Australia, which implies that information on PHR practices in European countries is still lacking. Moreover, the association between PHR and sexual behavior per se has not yet been well addressed in research. Therefore, the aim of the present study was to extend previous research on PHR practices by exploring the reasons why women and men do or do not engage in PHR, by studying the association between PHR and sexual behavior and by comparing attitudes toward PHR practices, PHR behavior, and associated factors between men and women.

\section{METHODS}

\section{Survey and Participants}

In 2011, an online survey on PHR behavior of men and women was performed in Flanders (the Northern part of Belgium). This online survey was promoted by a popular progressive weekly magazine in both its printed (approximately 150,000 copies) and online (digital newsletter) versions and was advertised through a short column based on an interview in which the researcher's interest in "how people really think about PHR and how these practices relate to their sexuality" was advocated and in which the link to the online study was mentioned. Readers who followed this link could answer the survey questions on sociodemographic characteristics, PHR behavior, sexuality-related questions, and partner relationship quality. The study was approved by the Ethics Committee of the Faculty of Medicine of KU Leuven.

\section{Main Outcome Measures}

\section{Sociodemographic Data}

Participants were asked to indicate their current age (categorically measured, ie, age $<15$ years, $15-20$ years, $20-30$ years, $30-40$ years, $40-50$ years, $50-60$ years, or $>60$ years), relationship status (ie, not in a relationship, partnered but not living together, living together with a partner, or married), and sexual orientation based on self-identification (ie, heterosexual, bisexual, homosexual, or asexual).

\section{PHR Practices}

Participants were asked about their own previous and current PHR practices (ie, not at all; currently not, but I did remove it [partially] before; currently not, but I do cut or trim it; currently not, but I do cut and trim it and I have removed it [partially] before; partially; and completely), the PHR practices of their partner (ie, not at all; he/she cuts or trims it, partially, or completely), and the inclination to have sex when pubic hair had recently been removed, (ie, not, less, equally, or more inclined to have sex) and when pubic hair had not been removed (ie, not, less, equally, or more inclined to have sex). The methods of pubic hair modification or removal (eg, shaving, waxing) that participants used were not addressed in this study.

\section{Sexual Activity Status and History}

Participants were asked to indicate whether at the moment of the study they had sexual interactions with 1 partner, had sexual interactions with more than 1 partner, or were not sexually active. They were also asked at what age they first had sexual intercourse (defined as vaginal or anal penetration) and how many sexual partners they had in their lifetime.

\section{Reasons For and Against PHR}

Participants were asked to report why they removed their pubic hair. They could do so by indicating if 1 or more of the following reasons were applicable: "because my friends say they do it," "because my partner wants it," "because my religion prescribes it," "because it makes me feel more feminine/masculine," "because I like to feel soft," "because it is trendy," "because I think it makes sex better," "because I feel more comfortable when receiving oral sex," "because I think it is more hygienic," "because I think it is a form of self-expression," "because it makes me feel naughtier," and, only for men, "because I think that my penis then looks bigger."

Participants were also asked to report the importance of each reason on a 5-point Likert-scale ranging from "not important at all" to "very important." Participants were asked to do the same for the following reasons for not removing their pubic hair: "because I do not see the value of it," "because my partner prefers 
it," "because it has too many (physical) side effects (eg, skin rash, itching, bumps)," "because if pubic hair exists, it must have a function," "because I think it is more natural," "because I do not want to give in to the demands that modern society puts on us," "because I do not think it makes a difference for sexuality anyway," and, for men only, "because I think it is something for women and not for men."

\section{PHR Expectations}

Expectations regarding PHR were evaluated by asking participants what they expect of their partner regarding PHR (ie, "not to remove their pubic hair," "to partially remove their pubic hair," "to totally remove their pubic hair," or "to do as they want themselves"), as well as what their partner expects of them and why; that is, "my partner finds it important that I (partially) remove my pubic hair because..." "they find it more attractive," "they find it sexier," "everybody does it," "they remove their own pubic hair," "they do not like to give me oral sex if my pubic hair is not (partially) removed," "they find sex more satisfying if I (partially) remove my pubic hair," "they find it nonhygienic if I do not (partially) remove my pubic hair," or "they do not find it important whether I remove my pubic hair."

\section{Partner Relationship Quality}

Partner relationship quality was measured with the Maudsley Marital Questionnaire (MMQ), a standardized and validated questionnaire consisting of 15 items relating to marital (MMQ$\mathrm{M})$ and sexual satisfaction (MMQ-S) with a 9-point (0-8) scale appended to each question. Total scores on the MMQ-M range from 0 to 80 , and total scores on the MMQ-S range from 0 to 40 , with higher scores reflecting greater dissatisfaction. In this sample, the Cronbach's $\alpha$ values for MMQ-M and MMQ-S were .91 and .81, respectively, for men and .92 and .76, respectively, for women.

\section{Data Analysis}

Descriptive statistics were used to assess participant characteristics. The independent Student's $t$ test was used to compare relationship and sexual satisfaction across gender and against dichotomous PHR variables. The $\chi^{2}$ test was used to detect associations between PHR and the variables of this study within and across gender. The significance level was set at $P<.05$. All statistical analyses were performed using SPSS for Windows, version 22.0 (IBM, Armonk, NY, USA).

\section{RESULTS}

\section{Participants}

A total of 4,585 participants completed the online survey. Because participants aged $<15$ years and participants selfidentifying as asexual were poorly represented in this sample, they were excluded from further data analysis. Furthermore, the variable reflecting participants' age at first sexual intercourse
Table 1. PHR practices

\begin{tabular}{lcc}
\hline & $\%$ & $\%$ \\
Practice & Men & Women* \\
\hline Not at all & 21.1 & 3.1 \\
\hline Currently not, but I did remove it in the past & 4.7 & 1.5 \\
Currently not, but I do cut or trim it & 21.8 & 7.6 \\
Currently not, but I do cut or trim it and have & 13.2 & 7.6 \\
$\quad$ removed it in the past & 20.7 & \\
Partially & & 15.4 \\
Partially, in function of the bikini line & & 34.1 \\
Partially, more than the bikini line & 18.4 & 30.8 \\
\hline
\end{tabular}

$\mathrm{PHR}=$ pubic hair removal.

${ }^{*} \chi^{2}=1388.28, P<.001$.

showed missing values and significant outliers. After excluding cases with missing values and standardizing data on this variable, cases with a $z$-score $<-1.96$ (corresponding to age at first sexual intercourse $<12$ years) and $>3.29$ (corresponding to age at first sexual intercourse $>28$ years) were also excluded from further analyses. The remaining 4,422 participants included 2,687 men and 1,735 women.

\section{PHR Practices}

In total, $80.3 \%$ of the women reported current partial or total PHR, and only $3.1 \%$ of women reported never having removed their pubic hair. Among the men, 39.1\% reported current partial or total PHR, and $21.1 \%$ reported never having engaged in any PHR practice. The prevalence and extent of PHR differed significantly between men and women $\left(\chi^{2}=1,388.28 ; P<\right.$ .001) (Table 1).

\section{PHR and Sociodemographic Characteristics}

Demographic characteristics of the sample and their associations with PHR are shown in Table 2. In men, self-reported PHR practices differed significantly among age groups $\left(\chi^{2}=\right.$ 99.14; $P<.001$ ), with more middle-aged and older men engaging in PHR. PHR practices in men were also significantly associated with sexual orientation $\left(\chi^{2}=12.62 ; P=.001\right)$, with more bisexual men engaging in PHR compared with heterosexual and homosexual men. Furthermore, men's PHR practices were found to be significantly associated with relationship status $\left(\chi^{2}=31.40 ; P<.001\right)$ and sexual activity status $\left(\chi^{2}=23.51 ; P\right.$ $<.001)$. Married men and men who were sexually active with several partners were most likely to remove their pubic hair. Finally, an association was found between men's PHR practices and their partner's practices $\left(\chi^{2}=273.44 ; P<.001\right)$. Almost one-half $(49.5 \%)$ of the men whose partner engaged in (partial) PHR reported also removing their pubic hair, compared with only $16.1 \%$ of men whose partner was not removing their pubic hair (Table 2).

In women, self-reported PHR practices also differed significantly between age groups $\left(\chi^{2}=40.90 ; P<.001\right)$, with more 
Table 2. Sociodemographic characteristics and PHR practices

\begin{tabular}{|c|c|c|c|c|c|c|c|}
\hline \multirow[b]{2}{*}{ Characteristic } & \multicolumn{3}{|c|}{ Men $(N=2,687)$} & \multicolumn{3}{|c|}{ Women $(\mathrm{N}=1,735)$} & \multirow[t]{2}{*}{$\chi^{2 *}$} \\
\hline & $\%(\mathrm{n})$ & $\% \mathrm{PHR}$ & $\chi^{2+}$ & $\%(n)$ & $\%$ PHR & $\chi^{2 \dagger}$ & \\
\hline Age, yr & & & 99.14 & & & 40.90 & \\
\hline $15-20$ & 7.9 (211) & 28.4 & & 15.6 (270) & 87.8 & & 176.58 \\
\hline $20-30$ & 31.7 (851) & 28.6 & & $48.1(834)$ & 82.7 & & 500.33 \\
\hline $30-40$ & $21.0(564)$ & 39.7 & & $16.4(284)$ & 76.1 & & 99.92 \\
\hline $40-50$ & $19.1(514)$ & 51.8 & & 11.7 (203) & 77.3 & & 39.39 \\
\hline $50-60$ & $13.9(374)$ & 47.9 & & 6.9 (119) & 66.4 & & 12.24 \\
\hline $60+$ & 6.4 (173) & 45.1 & & $1.4(25)$ & 56.0 & & 1.05 \\
\hline Sexual orientation & & & 12.62 & & & 2.83 & \\
\hline Heterosexual & $92.6(2,489)$ & 38.5 & & $91.5(1,588)$ & 79.8 & & 669.01 \\
\hline Bisexual & 3.7 (100) & 56.0 & & $6.3(110)$ & 83.6 & & 19.23 \\
\hline Homosexual & $3.6(98)$ & 36.7 & & $2.1(37)$ & 89.2 & & 29.58 \\
\hline Relationship status & & & 31.40 & & & 26.67 & \\
\hline Not in a relationship & 16.7 (449) & 31.0 & & 19.3 (335) & 79.7 & & 182.57 \\
\hline Partnered but not living together & $25.4(682)$ & 35.6 & & 34.5 (598) & 84.8 & & 317.28 \\
\hline Partnered and living together & $21.8(586)$ & 39.1 & & $25.8(447)$ & 81.9 & & 190.20 \\
\hline Married & 36.1 (970) & 45.3 & & $20.5(355)$ & 71.3 & & 70.47 \\
\hline Sexual activity status & & & 23.51 & & & 4.49 & \\
\hline Sexually active, with 1 partner & $79.6(2,139)$ & 39.4 & & $81.6(1,416)$ & 81.7 & & 590.93 \\
\hline Sexually active, with several partners & $8.7(234)$ & 49.6 & & $6.2(108)$ & 84.3 & & 37.21 \\
\hline Not sexually active & 11.7 (314) & 29.3 & & 12.2 (211) & 75.4 & & 107.28 \\
\hline PHR partner & & & 273.44 & & & 75.70 & \\
\hline No $\mathrm{PHR}^{\ddagger}$ & $31.6(848)$ & 16.2 & & $66.0(1,145)$ & 74.3 & & 659.40 \\
\hline $\mathrm{PHR}^{5}$ & $68.4(1,839)$ & 49.6 & & $34.0(590)$ & 91.9 & & 331.46 \\
\hline
\end{tabular}

$\mathrm{PHR}=$ pubic hair removal.

${ }^{*} \chi^{2}$ between genders.

${ }^{+} \chi^{2}$ within gender.

${ }^{\ddagger}$ No PHR: "not at all" and "no, but he/she cuts or trims it."

sPHR: "partially" and "completely."

younger women engaging in PHR. Women's PHR practices were not significantly associated with sexual orientation $\left(\chi^{2}=\right.$ 2.83; $P>.05)$, but were significantly associated with relationship status $\left(\chi^{2}=26.67 ; P<.001\right)$. Fewer married women reported performing PHR compared with single women or women with 1 or more partners. The association between women's PHR and sexual activity was not significant $\left(\chi^{2}=4.49 ; P>.05\right)$. Women's PHR patterns were significantly associated with their partner's PHR patterns $\left(\chi^{2}=75.70 ; P<.001\right)$, with more women whose partner engaged in (partial) PHR also removing their pubic hair (Table 2).

Comparing men and women within each of the age groups, significantly more women than men engaged in PHR in all age categories except for the age $>60$ years group. Women were also more likely than men to remove their pubic hair in all sexual orientation, relationship status, and sexual activity status categories. Finally, significantly more women than men engaged in PHR regardless of the PHR practices of their partner.

\section{PHR and Sexual History}

The male participants were significantly older than the female participants at first sexual intercourse (mean age, $18.11 \pm 2.70$ years vs $17.24 \pm 2.25$ years; $\left.t_{(4,150)}=11.60 ; P<.001\right)$. The male participants had significantly more lifetime sexual partners compared with the female participants (mean $8.54 \pm 14.75$ vs $\left.6.25 \pm 9.32 ; t_{(4,418)}=6.33 ; P<.001\right)($ Table 3$)$.

In men, self-reported PHR was not associated with age at first sexual intercourse $\left(\chi^{2}=1.75 ; P>.05\right)$, but it was significantly associated with the number of lifetime sexual partners. Men with $\leq 4$ sexual partners were less likely to perform PHR compared with men with $\geq 5$ sexual partners $\left(33.8 \%\right.$ vs $45.6 \% ; \chi^{2}=$ 38.78; $P<.001)$ (Table 3).

In women, the reverse pattern of associations was found. Selfreported PHR was not associated with the number of lifetime sexual partners $\left(\chi^{2}=0.005 ; P>.05\right)$, but it was significantly associated with age at first sexual intercourse $\left(\chi^{2}=13.82 ; P<\right.$ .001). More women who reported experiencing first sexual intercourse at age $\leq 17$ years engaged in PHR compared with women who reported first intercourse at age $\geq 18$ years $(83.1 \%$ vs $75.8 \%$ ) (Table 3 ).

\section{PHR and Sexual Behavior}

In men, $48.1 \%$ of those engaging in (partial) PHR reported to be more inclined to have sex after recent PHR. Men's inclination 
Table 3. PHR practices and sexual history

\begin{tabular}{|c|c|c|c|c|c|c|}
\hline \multirow[b]{2}{*}{ Sexual history } & \multicolumn{3}{|c|}{ Men $(N=2,687)$} & \multicolumn{3}{|c|}{ Women $(\mathrm{N}=1,735)$} \\
\hline & $\%(\mathrm{n})$ & $\% \mathrm{PHR}$ & $\chi^{2}$ & $\%(n)$ & $\% \mathrm{PHR}$ & $\chi^{2}$ \\
\hline Number of sexual partners & & & 38.78 & & & 0.01 \\
\hline$\leq 4$ & $55.1(1,480)$ & 33.8 & & $59.8(1,037)$ & 80.2 & \\
\hline$\geq 5$ & $44.9(1,207)$ & 45.6 & & $40.2(698)$ & 80.4 & \\
\hline Age at first intercourse, yr & & & 1.75 & & & 13.82 \\
\hline$\leq 17$ & $46.4(1,247)$ & 40.4 & & $62.0(1,075)$ & 83.1 & \\
\hline$\geq 18$ & $53.6(1,440)$ & 37.9 & & $38.0(660)$ & 75.8 & \\
\hline
\end{tabular}

$\mathrm{PHR}=$ pubic hair removal.

to behave sexually after recent PHR was not associated with their partner's PHR $\left(\chi^{2}=2.28 ; P>.05\right)$. When these men had not recently removed their pubic hair, $23.1 \%$ reported to be less inclined to have sex or to not have sex at all. Their inclination to have sex when their pubic hair was not recently removed was associated with their partner's PHR practice $\left(\chi^{2}=11.00 ; P=\right.$ .012). More men whose partner removed their pubic hair reported to be less inclined to have sex or to not have sex at all when they themselves had not removed their pubic hair (24\%) compared with men whose partner did not remove their pubic hair $(16.8 \%)$.

In women, $58.7 \%$ of those engaging in (partial) PHR reported to be more inclined to have sex after recent PHR. Women's inclination to behave sexually after recent PHR was associated with their partner's PHR practice $\left(\chi^{2}=7.14 ; P=.028\right)$. More women with a pubic hair-removing partner reported to be more inclined to have sex after recent PHR (62.7\%) compared with women whose partner did not remove their pubic hair (56.2\%). When these women had not recently removed their pubic hair, $43.1 \%$ reported to be less inclined to have sex or to not have sex at all. Their inclination to have sex after not having removed their pubic hair was also significantly associated with their partner's PHR practices $\left(\chi^{2}=8.42 ; P=.038\right)$. More women with a pubic hair-removing partner reported to be less inclined to have sex or to not have sex at all when they had not recently removed their pubic hair (45.9\%) compared with women whose partner did not remove their pubic hair (41.3\%).

Overall, women were more likely than men to have sex after recent PHR $\left(\chi^{2}=28.15 ; P<.001\right)$ and more likely to report being less inclined to have sex or to not have sex at all when they had not recently removed their pubic hair $\left(\chi^{2}=112.47\right.$; $P<$ $.001)$.

\section{Reasons For and Against PHR}

When asked about why they removed their pubic hair, the men in our study endorsed the following reasons as most important: (i) "because I feel more comfortable when receiving oral sex" (39.3\%); (ii) "because I think it is more hygienic" (39\%); (iii) "because I like to feel soft" (36.6\%); and (iv) "because my partner wants it" (35.6\%). Men who reported not removing their pubic hair said they did not do it mostly because of their partner's preference (51.6\%). Side effects, such as skin rushes, itching, or bumps, were reported as the second most important reason for not removing pubic hair (47.6\%).

Women in our study reported removing their pubic hair most often because: (i) "I feel more comfortable when receiving oral sex" (74.9\%); (ii) "I feel more feminine when I remove my pubic hair" (66.6\%); (iii) "I like to feel soft" (63.2\%); and (iv) "my partner wants it" (62.2\%). Women who did not remove their pubic hair reported not doing so mostly because of side effects, such as skin rash, itching, or bumps $(66.7 \%)$ or because their partner prefers them not to (43.9\%).

\section{PHR and Partner Expectations}

When asked what they expect of their partner in terms of PHR, $51.8 \%$ of the men in our study reported that they expect their partner to (partially) remove their pubic hair and 6.6\% expected their partner to not engage in PHR (Table 4). This percentage varied significantly based on age $\left(\chi^{2}=100.89\right.$; $P<$ .001), sexual orientation $\left(\chi^{2}=28.24 ; P<.001\right)$, and relational status $\left(\chi^{2}=22.34 ; P=.001\right)$, but not based on sexual activity status $\left(\chi^{2}=2.07 ; P>.05\right)$. Of those who expected their partner to engage in PHR, $79.7 \%$ reported that their partner actually did (partially) remove their pubic hair. Of those who expected their partners to not remove their pubic hair, only $10.7 \%$ reported that their partner engaged in PHR. When asked what their partners expected of them, $45.7 \%$ of men reported that their partner does not find PHR important. When no PHR expectations were perceived, significantly more men reported not removing their pubic hair compared with men who did perceive that their partners expected them to engage in PHR (80.4\% vs $\left.44.5 \% ; \chi^{2}=360.56 ; P<.001\right)$.

Of the women in our study, $32 \%$ reported that they expected their partner to (partially) remove their pubic hair and $20.4 \%$ expected their partner not to remove it (Table 4). This percentage did not differ based on age $\left(\chi^{2}=12.62 ; P>.05\right)$ or relational status $\left(\chi^{2}=10.40 ; P>.05\right)$, but it did vary based on sexual orientation $\left(\chi^{2}=11.76 ; P=.019\right)$ and sexual activity status $\left(\chi^{2}=21.72 ; P<.001\right)$. Of those women who expected their partner to engage in PHR, 59.3\% reported that their 
Table 4. PHR expectations and partner PHR

\begin{tabular}{|c|c|c|c|c|c|c|}
\hline \multirow[b]{3}{*}{ Expectations } & \multicolumn{3}{|c|}{ Men $(N=2,687)$} & \multicolumn{3}{|c|}{ Women $(\mathrm{N}=1,735)$} \\
\hline & \multirow[b]{2}{*}{ n (\%) } & \multicolumn{2}{|c|}{ Partner PHR } & \multirow[b]{2}{*}{ n (\%) } & \multicolumn{2}{|c|}{ Partner PHR } \\
\hline & & $\%$ & $\chi^{2}$ & & $\%$ & $\chi^{2}$ \\
\hline Expectations & & & 367.79 & & & 318.62 \\
\hline No PHR & 177 (6.6) & 10.7 & & 354 (20.4) & 2.5 & \\
\hline PHR & 1392 (51.8) & 79.7 & & 555 (32.0) & 59.3 & \\
\hline No expectations & 1118 (41.6) & 63.5 & & $826(47.6)$ & 30.5 & \\
\hline
\end{tabular}

$\mathrm{PHR}=$ pubic hair removal.

partners actually did so. Of those who expected their partners not to remove their pubic hair, only $2.5 \%$ reported that their partner engaged in PHR. Regarding the expectations of their partners as they perceived them, $28.3 \%$ of the female participants reported that their partner did not find PHR important. When no such expectations were perceived, significantly more women reported not removing their pubic hair compared to when women did perceive that their partners expected them to engage in PHR (37.5\% vs $\left.12.7 \% ; \chi^{2}=136.52 ; P<.001\right)$.

Overall, men and women differed significantly in their expectations regarding the PHR of their partners $\left(\chi^{2}=270.25 ; P\right.$ $<.001)$. More men than women expected their partner to remove their pubic hair, while more women than men expected their partner to not remove it.

\section{PHR and Relationship and Sexual Satisfaction}

In general, relationship satisfaction did not differ significantly between men and women (mean score, $26.83 \pm 13.70$ vs 26.30 $\left.\pm 14.24 ; t_{(4,420)}=1.23 ; P>.05\right)$; neither differed sexual satisfaction between men and women $(15.47 \pm 8.35$ vs $15.62 \pm$ 8.24; $\left.t_{(4,420)}=-.59 ; P>.05\right)$. Some differences were found in relationship and sexual satisfaction between men and women as functions of their own PHR, their partner's PHR, or the degree of alignment between expectations and PHR behavior (Table 5).

For men, relationship and sexual satisfaction did not show any variation based on their own PHR behavior or on its alignment with their partner's expectations. However, both relationship satisfaction and sexual satisfaction were associated with their partner's PHR practices and whether or not these were in line with the men's expectations.

Women's relationship satisfaction did not differ based on actual PHR behavior, but it did show differences based on the alignment between (partner) PHR behavior and (partner) expectations. Women's sexual satisfaction was shown to be associated with both actual PHR behavior and whether or not that behavior is aligned with reciprocal expectations between partners.

\section{DISCUSSION}

The aim of the present study was to explore self-reported PHR practices and their associations with demographic, relational, and sexual characteristics in men and women. We found that (i) PHR is a widespread practice among women and men, replicating earlier research findings ${ }^{7,8,14-16}$; (ii) the prevalence of PHR among men is significantly lower than in women ${ }^{16}$ regardless of age, sexual orientation, relationship status, sexual activity status, and whether or not their partner engaged in PHR; (iii) PHR is associated with age, sexual activity, relationship status, and partner's PHR practice; and (iv) in men, PHR is also associated with sexual orientation. ${ }^{18}$ Finally, we found that in men, PHR is associated with the number of lifetime sexual partners, whereas in women, there is an association between PHR and age at first sexual intercourse.

Our finding that in women, unlike in men, PHR is not associated with sexual orientation, sexual activity status, or number of lifetime sexual partners is in contrast to previously reported findings. $3,7,8,10,16$ Our results may be explained by the fact that the proportion of women engaging in PHR was so high, approximately $80 \%$, that variations based on these factors were difficult to detect. Alternatively, our results can be considered supportive of earlier findings, ${ }^{14,19}$ suggesting that PHR is more strongly integrated into women's self-views, whereas for men it is related to a specific relational and sexual context. Our finding that men mostly remove their pubic hair when older, married, and having had 5 or more sexual partners - which corroborates previous research ${ }^{15,16}$ - supports the idea that for men, PHR is a behavior learned through their relational interactions and history.

Overall, in our present series, men were less likely than women to engage in PHR. When asked why they did not remove their pubic hair, one-third of the men said they considered PHR more appropriate for women than for men. In line with these reports, very few men reported engaging in PHR to feel more masculine, whereas a high percentage of women endorsed "feeling more feminine" as a reason to remove their pubic hair, corroborating earlier research reports. ${ }^{4,11,20}$ These results suggest that both men and women adhere to social norms that link hairiness to masculinity and hairlessness to femininity. ${ }^{12,20,21}$ The fact that men remove their pubic hair less often than women do can be considered a behavioral expression of this adherence, demonstrating that men and women are equally susceptible to social pressures. It just seems that society prescribes different normative behavior for men than for women when it comes to their pubic hair. 


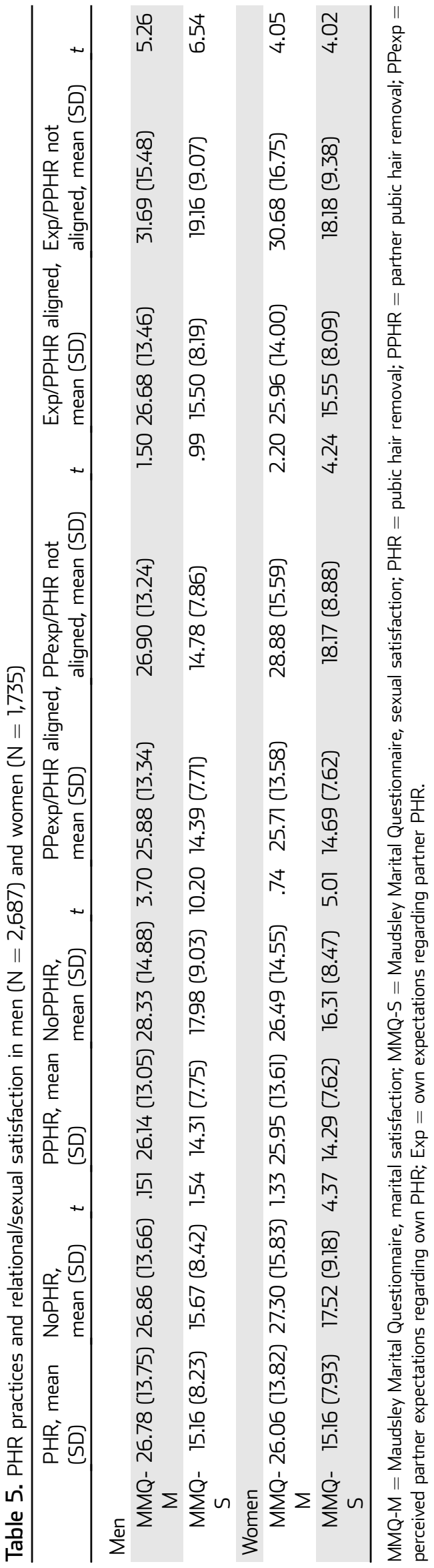

Despite this evidence of their importance, societal trends and other distal sources of influence (eg, friends, religion) are often not endorsed to explain individual PHR behavior, ${ }^{4,20}$ and were the factors least acknowledged by our study participants. Interestingly, social norms regarding PHR seem to be accurately reflected in the expectations that men and women have of each other. We found that more men than women expect their partners to remove their pubic hair, replicating earlier findings on male preferences, ${ }^{16,22}$ whereas more women than men expected their partner to not remove their pubic hair. Considering that partner expectations are explicitly acknowledged as reasons guiding men's and women's PHR choices, it seems plausible that partner expectations are the vehicle through which social norms indirectly affect men's and women's PHR behavior.

The significance of partner expectations ${ }^{21}$ is even further supported by our study. PHR seems to have close ties with and to gain meaning within partner relationships, as both men and women report explicitly taking into account their partner's preferences in their decision to (not) remove their pubic hair and align their behavior to that of the partner. Our finding that married women engage in PHR less often than women with other relationship statuses, along with the finding that more married men expect their partner to not remove their pubic hair,* clearly illustrate this alignment between partner expectations and PHR. The importance of this alignment becomes clear through its found associations with relationship and sexual satisfaction, which reinforce the suggestion that partner preferences are important determinants of PHR behavior of men and women.

In our view, the paramount role of the partner in PHR supports PHR's distinctiveness from the removal of other body hair $^{21}$ and its connection to sexuality in both men and women. ${ }^{9,11,19,23}$ This connection becomes evident when considering the reason for PHR that was most widely endorsed by men and women alike: because they then feel more comfortable when receiving oral sex. Our finding that both men and women who normally engage in PHR but who had not recently removed their pubic hair were less inclined to have sex when they had a pubic hair-removing partner offers additional support for the link between PHR and sexuality.

Based on the aforementioned evidence, we conclude that PHR is a normative practice with a clear relational and sexual character, and that all these aspects are necessary to understand its antecedents and continuation.

\section{Strengths and Limitations}

A major strength of this study is that it is the first study to provide data on PHR patterns and their association with sexual

\footnotetext{
* [1] "Although this conclusion only applies to mixed-sex marriages, 95.2\% of the married participants in our study reported to be heterosexual, which led us to infer that their marriage is a mixed-sex one."
} 
behavior in a large sample of men and women living in Flanders (the Northern part of Belgium). In addition, the simultaneous collection of data on behavioral (eg, PHR prevalence, sexual behavior) and attitudinal level (eg, reasons and expectations regarding PHR), from men and women, allowed to better understand the relational underpinnings of PHR. However, our relatively large sample size cannot fully compensate for the fact that this study relies on a convenience sample and thus may be strongly biased. Besides volunteer bias, participants were recruited among readers of a popular (left wing) weekly magazine that is read mostly by more progressive and educated men and women. $^{24,25}$ Although educational attainment has not been related to $\mathrm{PHR},{ }^{8}$ progressive societal beliefs place this magazine's readers within a social context that is not completely representative of the general population. Consequently, the reported attitudes and practices could be less representative as well. Another limitation is that the mediatized context of the study precluded us from collecting additional demographic information (eg, level of education, relationship duration, health status) that might impact, mediate or moderate PHR practices and that might have helped to better contextualize our findings. Furthermore, in the absence of well-validated instruments, most data for this study were collected using a self-designed questionnaire. Although we have tried to increase its face validity by drawing on the available literature and by consulting experts in the field, the use of a nonvalidated measure can be considered a limitation. A final limitation is that the study is based on a cross-sectional design. This implies that the results seen in the different age groups could also partially reflect specific cohort effects rather than age effects per se. ${ }^{26}$

\section{Implications for Clinical Practice and Future Research}

Our present findings on PHR in men and women contribute to our understanding of this practice in the European context. Combined with information from the medical discipline on the function and risks of PHR, it can help clinicians identify groups that might be most affected by PHR-related health risks, educate these patients, and formulate guidelines for their care when confronted with a PHR problem, such as those formulated by Trager. ${ }^{27}$ By aligning these guidelines and care with the reasons why people engage in PHR, these guidelines and care may be better and more widely adopted, leading to better health results.

Although this study contributes to the scarce body of research on PHR of both genders, it has also unveiled differences between men and women that merit further investigation. First, our findings suggest that profiles of men and women who remove their pubic hair differ in terms of age and relationship status. PHR practices are more homogenous in women than in men when it comes to sexual orientation, sexual activity status, and number of lifetime sexual partners. Furthermore, men and women differ in terms of the degree to which PHR plays a role in their sexual decision making. Both quantitative and qualitative research on behavioral, personal, relational, and sexual motives of men and women for performing PHR may help explain these differences.

Related to behavioral motives, the fact that men are less likely than women to remove their pubic hair demonstrates the need for further research on the different PHR norms for men and women. In addition, studies could focus on the finding that men as well as women are more likely to partially, not completely, remove their pubic hair, to evaluate how this relates to hairlessness' as a norm. ${ }^{11,20,21,28}$ and what partial as opposed to complete removal suggests about adherence to that norm by both men and women. Finally, the role of the partner on a person's PHR practice is another important issue to consider for future research. Indeed, the associations found in the current study give reason to believe that partner variables may play a significant role in the PHR practices of both men and women.

\section{CONCLUSION}

Despite significant differences between the genders, the present study suggests that PHR is a widespread practice among both men and women that seems to be associated with behavioral, personal, relational, and sexual motives and partner preferences. The question "to shave or not to shave" seems to be a personally, relationally and sexually inspired conundrum, and only time (and timely research) will inform us more about its further evolution.

Corresponding Author: Paul Enzlin, PhD, Institute for Family and Sexuality Studies, p/a: UZ Leuven, Herestraat 49, B-3000 Leuven, Belgium; E-mail: paul.enzlin@uzleuven.be

Conflicts of interest: The authors report no conflicts of interest.

Funding: None.

\section{STATEMENT OF AUTHORSHIP}

\section{Category 1}

(a) Conception and Design

Paul Enzlin; Kaat Bollen; Jan Deprest

(b) Acquisition of Data

Paul Enzlin; Kaat Bollen; Sofia Prekatsounaki; Liesbeth Hidalgo; Leen Aerts

(c) Analysis and Interpretation of Data

Paul Enzlin; Kaat Bollen; Sofia Prekatsounaki; Liesbeth Hidalgo; Leen Aerts; Jan Deprest

\section{Category 2}

(a) Drafting the Article Paul Enzlin; Sofia Prekatsounaki; Liesbeth Hidalgo; Leen Aerts

(b) Revising It for Intellectual Content Paul Enzlin; Kaat Bollen; Sofia Prekatsounaki; Liesbeth Hidalgo; Leen Aerts; Jan Deprest

\section{Category 3}

(a) Final Approval of the Completed Article Paul Enzlin; Kaat Bollen; Sofia Prekatsounaki; Liesbeth Hidalgo; Leen Aerts; Jan Deprest 


\section{REFERENCES}

1. Ramsey S, Sweeney C, Fraser M, et al. Pubic hair and sexuality: A review. J Sex Med 2009;6:2102-2110.

2. Glass AS, Bagga HS, Tasian GE, et al. Pubic hair grooming injuries presenting to US emergency departments. Urology 2012;80:1187-1191.

3. DeMaria AL, Flores M, Hirth JM, et al. Complications related to pubic hair removal. Am J Obstet Gynecol 2014;210:528; e1-e5.

4. Riddell L, Varto H, Hodgson ZG. Smooth talking: The phenomenon of pubic hair removal in women. Can J Hum Sex 2010;19:121.

5. Schmidtberger $L$, Ladizinski B, Ramirez-Fort MK. Wax on, wax off: Pubic hair grooming and potential complications. JAMA Dermatol 2014;150:122.

6. Desruelles F, Cunningham SA, Dubois D. Pubic hair removal: A risk factor for 'minor' STI such as molluscum contagiosum? Sex Transm Infect 2013;89:216.

7. Bercaw-Pratt $J L$, Santos XM, Sanchez J, et al. The incidence, attitudes and practices of the removal of pubic hair as a body modification. J Pediatr Adolesc Gynecol 2012;25:12-14.

8. Demaria AL, Berenson AB. Prevalence and correlates of pubic hair grooming among low-income Hispanic, Black, and White women. Body Image 2013;10:226-231.

9. Herbenick D, Hensel D, Smith NK, et al. Pubic hair removal and sexual behavior: Findings from a prospective daily diary study of sexually active women in the United States. J Sex Med 2013;10:678-685.

10. Herbenick D, Schick V, Reece M, et al. Pubic hair removal among women in the United States: Prevalence, methods, and characteristics. J Sex Med 2010;7:3322-3330.

11. Toerien M, Wilkinson S. Exploring the depilation norm: $A$ qualitative questionnaire study of women's body hair removal. Qual Res Psychol 2004;1:69-92.

12. Toerien M, Wilkinson S, Choi PYL. Body hair removal: The 'mundane' production of normative femininity. Sex Roles 2005;52:399-406.

13. McDougall LJ. Towards a clean slit: How medicine and notions of normality are shaping female genital aesthetics. Cult Health Sex 2013;15:774-787.

14. Martins $Y$, Tiggemann $M$, Churchett L. Hair today, gone tomorrow: A comparison of body hair removal practices in gay and heterosexual men. Body Image 2008;5:312-316.
15. Basow SA, O'Neil K. Men's body depilation: An exploratory study of United States college students' preferences, attitudes, and practices. Body Image 2014;11:409-417.

16. Butler SM, Smith NK, Collazo E, et al. Pubic hair preferences, reasons for removal, and associated genital symptoms: Comparisons between men and women. J Sex Med 2015; 12:48-58.

17. Herbenick D, Reece M. Development and validation of the Female Genital Self-Image Scale. J Sex Med 2010;7:18221830.

18. Gaither TW, Truesdale M, Harris CR, et al. The influence of sexual orientation and sexual role on male grooming-related injuries and infections. J Sex Med 2015;12:631-640.

19. Smolak L, Murnen S. Gender, self-objectification and pubic hair removal. Sex Roles 2011;65:506-517.

20. Tiggemann M, Kenyon S. The hairlessness norm: The removal of body hair in women. Sex Roles 1998;39:873-885.

21. Tiggemann M, Hodgson S. The hairlessness norm extended: Reasons for and predictors of women's body hair removal at different body sites. Sex Roles 2008;59:889-897.

22. Mazloomdoost D, Crisp CC, Westermann LB, et al. Survey of male perceptions regarding the vulva. Am J Obstet Gynecol 2015;213:731; e1-.e9.

23. Gaither TW, Awad MA, Osterberg EC, et al. Prevalence and motivation: Pubic hair grooming among men in the United States. Am J Mens Health 2017;11:620-640.

24. De lezers van Humo. Retrieved 12 december 2017, from http:// www.persgroepadvertising.be/nl/onze-merken/humo/humo\#tabs-2

25. De surfers van Humo.be. Retrieved 12 december 2017, from http://www.persgroepadvertising.be/nl/onze-merken/humo/hu mobe\#tabs-2

26. Araujo AB, Mohr BA, McKinlay JB. Changes in sexual function in middle-aged and older men: Longitudinal data from the Massachusetts Male Aging Study. J Am Geriatr Soc 2004; 52:1502-1509.

27. Trager JDK. Pubic hair removal-pearls and pitfalls. J Pediatr Adolesc Gynecol 2006;19:117-123.

28. Toerien M, Wilkinson S. Gender and body hair: Constructing the feminine woman. Women Stud Int Forum 2003;26:333344. 